\title{
Natural and human-driven fire regime and land-cover changes in Central and Eastern Europe
}

\author{
Angelica Feurdean 1 and Boris Vannière ${ }^{2}$ \\ GPWG2 workshop, Frankfurt am Main, Germany, 5-8 December 2016
}

This workshop sought to expand the scope of the Global Paleofire Working Group (GPWG2), both by introducing the Global Charcoal Database (GCD; www.paleofire.org) to potential new contributors and users from Central and Eastern Europe, and to encourage them to present their datasets and initiate collaborative research using the GCD database. Twenty-six attendees, almost half early-career researchers, with expertise in past fire, vegetation, anthropogenic impact, land-cover changes, and climate participated in this workshop.

Although the continually increasing number of charcoal records in GCD has enabled a number of regional-to-global syntheses of trends in biomass burning (e.g. Marlon et al. 2016), the paucity of charcoal records from Central and Eastern Europe in the global databases has hampered a coherent synthesis of temporal pattern in biomass burning and associated fire-stakes in this region. Focusing on Central and Eastern Europe, this workshop aimed to fill the gaps in our understanding of fire-regime dynamics, under a range of past environmental conditions and anthropogenic land uses, in a region that contains fire-prone ecosystems of high conservation value on the one hand, yet lacks the knowledge of the optimal fire regimes to preserve their functioning on the other (Feurdean et al. 2017). The first session introduced the attendees and facilitated familiarization with the datasets available for the reconstruction of past fire activity in Central and Eastern Europe. The second session combined both instruction and hands-on statistical tool use with the GCD and "paleofire" R-package (Blarquez et al. 2014), to develop regional syntheses of patterns in past fire activity. To achieve this, all attendees brought and compiled almost 50 new charcoal datasets from Central and Eastern Europe to produce the very first subregional-to-regional paleofire synthesis for this part of Europe (Fig. 1). The third session was dedicated to sub-group and plenary discussions covering three key topics: (i) the interpretation of the preliminary regional and sub-regional cumulative curves; (ii) plenary lectures on proxy-based and modeled Holocene variation in climate conditions, land cover and population density changes; offering a background on the past environmental conditions and level of anthropogenic impact; and (iii) discussions related to statistical approaches to charcoal time series

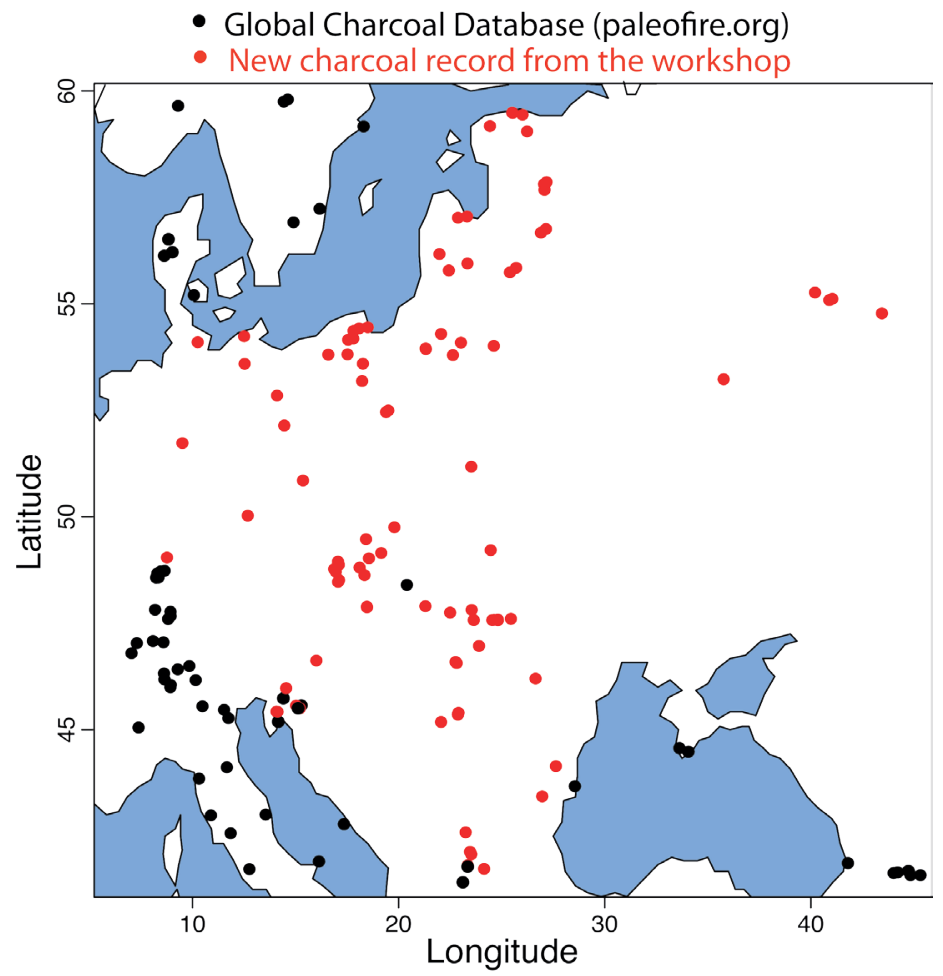

Figure 1: Distribution of our new charcoal records from Central and Eastern Europe in the Global Charcoal

Database (www.paleofire.org).

analyses and charcoal counting methodologies. A common theme in discussions was the importance of disentangling natural from human-driven fires, the role of anthropogenic fire on landscape dynamics, and the effects of fire on vegetation.

Our preliminary results over the entire region indicate the following major phases in the trajectory of fire activity over the Holocene: the highest fire activity between 10-8 ka; a low activity between 8-3 ka; a re-increase in fire activity from 3 ka towards the modern times before a final decrease over the last century. Interestingly, separated in two regions, Central and Eastern Europe show a distinctly different pattern in fire activity during the late Holocene; a decline in Central Europe as opposed to an increase in Eastern Europe. Following the workshop, we augmented this new Central and Eastern Europe dataset with ca. 70 additional records and metadata information, and are in the process of evaluating the sub-regional composite records against other proxybased and modeled datasets of past climate, vegetation, and land-cover changes. In the coming months, our group will focus on examining the following key research questions: How has biomass burning varied along ecological and climatic gradients? What is the link between biomass burning and land-cover changes in this region? How has anthropogenic use of fire changed over time, for example with shifts in land-use strategies and landscape fragmentation?

We conclude that this workshop provided an excellent opportunity to introduce the GCD both to potential new contributors and users, and to address a geographical "data gap" leading to important new collaborative research. We also invite other scientists and data contributors from this part of Europe to join our research initiative.

\section{AFFILIATIONS}

'Senckenberg Biodiversity and Climate Center, Frankfurt am Main, Germany

'Laboratoire Chrono-environnement UMR CNRS, Besançon, France

CONTACT

Angelica Feurdean: angelica.feurdean@gmail.com REFERENCES

Blarquez O et al. (2014) Comput Geosci 72: 255-261 Feurdean A et al. (2017) Forest Ecol Manag 389: 15-26 Marlon J et al. (2016) Biogeoscience 13: 3225-3244 